\title{
Atraso vacinal e seus determinantes: um estudo em localidade atendida pela Estratégia Saúde da Família
}

\author{
Immunization delay determinants: a study \\ in a place attended by Family Health Strategy
}

Gisele Cristina Tertuliano ${ }^{1}$ Airton Tetelbom Stein ${ }^{2}$

${ }^{1}$ Vigilância em Saúde, Secretaria de Saúde de Cachoeirinha. Rua Francisco Brochado da Rocha $79,1^{\circ}$ andar. 94935-200 Cachoeirinha RS. tertuliano@terra.com.br ${ }^{2}$ Grupo Hospitalar Conceição-RS.

\begin{abstract}
It is relevant to understand every aspect, regarding to strategies that will determine immunization coverage. Thus the main objective in this research is to identify the prevalence of depressive symptoms as well as low immunization uptake, identifying the caretakers' profile, considering his/her level of education, social-demographic character, marital status and also knowledge about immunization in which a Beck Inventory questionnaire was applied to the children's caretakers. Children's age ranged from 0 to 5 years and the number of subjects was 339 enrolled in a group of Family Health Strategy at the city of Cachoeirinha, in the state of Rio Grande do Sul, Brazil. The depression symptoms prevalence was $38.6 \%$. The association between depression symptoms and the low immunization uptake was not statistical significant $(O R=1.0, C I$ 95\%, 0.62-1.73). The low immunization uptake rate was $23.3 \%$. The high prevalence of depressive symptoms between mothers and the high percentage of immunization delay means the need of social help and the search of better effectivity of primary attention in health.
\end{abstract}

Key words Immunization, Depressive symptoms, Health service
Resumo O conhecimento dos determinantes da cobertura vacinal é relevante para o desenvolvimento de estratégias em Saúde Pública. Objetivou-se identificar a prevalência de sintomas depressivos, atraso vacinal e o perfil dos cuidadores em relação a escolaridade, situação sociodemográfica, estado civil e conhecimento sobre vacinação. A abordagem quantitativa foi escolhida utilizando-se um inquérito descritivo de base populacional, com a aplicação de um questionário e Inventário de Beck nos cuidadores de crianças na faixa etária de 0 a 5 anos, totalizando 339, numa equipe da Estratégia Saúde da Família no município de Cachoeirinha (RS). A prevalência de sintomas depressivos foi de 38,6\%. Não foi identificada associação significativa entre sintomas depressivos nos cuidadores e atraso vacinal nas crianças $(R C=1,0$, IC 95\%, 0,62-1,73). O percentual de atraso vacinal foi de 23,3\%. A alta prevalência de sintomas depressivos entre as mães e a alta percentagem de atraso vacinal indicam a necessidade de uma rede de apoio social e a busca de melhor efetividade da atenção primária em saúde.

Palavras-chave Atraso vacinal, Sintomas depressivos, Serviços de saúde 


\section{Introdução}

A atenção à saúde da criança vem ganhando visibilidade ao longo dos anos, através de programas que a promovem de forma integral, priorizando os grupos de risco, procurando qualificar a assistência e aumentar a cobertura dos serviços, possibilitando uma atenção de melhor qualidade. Enfocando a Assistência Integral à Saúde da Criança, seis ações básicas surgiram como respostas aos agravos mais frequentes na morbimortalidade de crianças de 0 a 5 anos de idade: aleitamento materno, orientação alimentar para o desmame, controle da diarreia, controle das doenças respiratórias na infância, imunização e acompanhamento do crescimento e do desenvolvimento $^{1,2}$. Espera-se com estas ações compor um conjunto de medidas que objetivem a realização de atividades preventivas, educativas, de diagnóstico, tratamento e recuperação, quando realizadas de forma integralizada e com qualidade, ocorrendo, assim, a redução da morbidade e da mortalidade infantil.

Segundo Macedo et al. ${ }^{3}$ e Miranda et $a l^{4}$, a imunização se reveste de particular interesse, pois considera o perfil epidemiológico das localidades, constituindo as vacinas benéficas e de baixo custo um dos fatores associados à redução da morbidade e da mortalidade infantil.

Mesmo nesse cenário de êxitos, é importante ressaltar que durante os encontros da família ou da criança com o serviço de saúde constata-se, através de relatos frequentes, que ainda existem crianças com atraso vacinal motivado por perda de oportunidade de vacinação, o que ocasiona prejuízo à cobertura.

É importante retratar a oferta e procura por imunobiológicos ${ }^{4,5}$, porém é necessário também relatar os fatores inerentes à rede de apoio, que é uma ferramenta essencial na criação da responsabilidade da família no cuidado com a saúde da criança. Descreve-se a relação dos determinantes socioeconômicos numa dimensão macrossocial, mas, muitas vezes, ignoram-se as dimensões psicológicas relacionadas ao cuidado em foco ${ }^{6-8}$. A situação social e familiar na qual a criança está inserida tem grande influência no desenvolvimento emocional dos cuidadores.

A rede social pode ser considerada a única possibilidade de ajuda com que as famílias carentes podem contar, sendo o único suporte para ajudar a aliviar as cargas da vida cotidiana9. As$\operatorname{sim}$, a pesquisa pretende investigar a frequência de sintomas depressivos no cuidador, o atraso vacinal (nos casos de crianças não vacinadas, no dia seguinte ao agendamento) e os potenciais fatores contribuintes, como perfil sociodemográfico e grau de instrução do cuidador.

\section{Métodos}

O Jardim Betânia, pertencente ao município de Cachoeirinha (RS), é circundado por duas rodovias, possui igrejas evangélica e católica, um centro de umbanda, uma unidade de saúde da família, comércio local (mercado, fruteira, armarinho), um ginásio de esportes, uma creche, um asilo e uma escola de ensino fundamental e médio. Nas suas cinco microáreas, cadastradas na Estratégia Saúde da Família (ESF), conforme o segmento territorial urbano, há 2.920 pessoas, sendo 665 na microárea 1,730 na microárea 2, 740 na microárea 3, 645 na microárea 4 e 720 na microárea 5 . $\mathrm{Na}$ época da coleta de dados, as famílias locais encontravam-se numa situação de vulnerabilidade social.

Foi realizado um inquérito descritivo de base populacional, e a coleta de dados foi realizada com os cuidadores de crianças com atraso vacinal e também com os cuidadores de crianças cujo calendário vacinal estava em dia. A maioria das coletas ocorreu no domicílio das famílias, devido à baixa frequência de usuários na sala de vacina.

Com referência à amostragem e ao cálculo do seu tamanho, considerou-se uma frequência de $10 \%$ de sintomas depressivos na população geral $^{10-12}$ e de $25 \%$ de sintomas depressivos entre os cuidadores que atrasaram a vacinação de suas crianças. No estudo de Carvalhaes e Benício ${ }^{13}$ sobre os sintomas depressivos e a desnutrição, relacionados à capacidade materna de cuidar, a razão de chances foi de 3,1, com IC 95\%, 0,910,3 . Portanto, o tamanho da amostra foi de 339 crianças, para um erro tipo I de 0,05 e erro tipo II de 0,20 . Incluíram-se os moradores na faixa etária citada, porém não se identificaram os cuidadores com dificuldade de compreensão em relação aos instrumentos, assim como as crianças hospitalizadas no período da coleta de dados. Os moradores que não estavam cadastrados pela ESF foram excluídos.

As variáveis independentes estudadas foram: idade, sexo, peso, altura e acompanhamento da curva de crescimento da criança, amamentação, permanência na creche, identificação do cuidador, sua idade, estado civil, grau de instrução, sintomas de depressão, seu conhecimento sobre vacinação, número de moradores no domicílio, número de filhos, posto em que costumam vaci- 
nar, problemas de saúde da criança que contraindicam de forma geral esta prática, motivo do atraso vacinal, perfil sociodemográfico e sintomas de depressão (Tabela 1). A variável dependente foi o atraso vacinal.
Os instrumentos de coleta de dados utilizados foram: questionário para avaliar a importância das vacinas, questionário de Beck para Avaliação de Sintomas Depressivos e o Questionário do Perfil Sociodemográfico do Critério de Clas-

Tabela 1. Fatores de ocorrência de atraso vacinal, considerando a análise bivariada, apresentando estimativa de razão de chances e intervalo de confiança 95\%, Cachoeirinha (RS), 2005.

\begin{tabular}{|c|c|c|c|c|c|c|}
\hline & $\mathbf{n}$ & $\%$ & $\begin{array}{l}\text { Prevalência de } \\
\text { atraso vacinal }\end{array}$ & RC & IC 95\% & p \\
\hline \multicolumn{7}{|l|}{ Idade da criança } \\
\hline 1 a 5 anos & 278 & 82,5 & 22,3 & 1 & - & \\
\hline$<1$ ano & 61 & 17,5 & 27,9 & 1,3 & $(0,72-2,52)$ & 0,45 \\
\hline \multicolumn{7}{|l|}{ Sexo da criança } \\
\hline Feminino & 173 & 51,5 & 22,5 & 1 & - & \\
\hline Masculino & 166 & 48,5 & 24,1 & 1,0 & $(0,66-1,80)$ & 0,83 \\
\hline \multicolumn{7}{|l|}{ Acompanhamento do crescimento } \\
\hline Sim & 287 & 84,7 & 23 & 1 & - & \\
\hline Não & 52 & 15,3 & 25 & 1,1 & $(0,56-2,22)$ & 0,89 \\
\hline \multicolumn{7}{|l|}{ Amamentação } \\
\hline Não & 174 & 51,3 & 20,1 & 1 & - & \\
\hline $\operatorname{Sim}$ & 165 & 48,7 & 26,7 & 1,4 & $(0,87-2,39)$ & 0,19 \\
\hline \multicolumn{7}{|l|}{ Cuidador } \\
\hline Outros & 37 & 10,9 & 18,9 & 1 & - & \\
\hline Mãe & 302 & 89,1 & 23,8 & 1,3 & $(0,57-3,18)$ & 0,64 \\
\hline \multicolumn{7}{|l|}{ Estado civil do cuidador } \\
\hline Casado & 161 & 47,5 & 21,1 & 1 & - & \\
\hline Não casado & 178 & 52,5 & 25,3 & 1,2 & $(0,26-2,01)$ & 0,44 \\
\hline \multicolumn{7}{|l|}{ Grau de instrução do cuidador } \\
\hline Analfabeto/primário incompleto & 170 & 50,1 & 24,7 & 1,7 & $(0,76-4,07)$ & 0,25 \\
\hline Ginasial completo/colegial incompleto & 63 & 18,6 & 20,6 & 1,3 & $(0,49-3,34)$ & 0,78 \\
\hline Primário completo/ginasial incompleto & 58 & 17,1 & 27,6 & 1,9 & $(0,74-4,93)$ & 0,27 \\
\hline Colegial completo/Superior incompleto & 48 & 14,2 & 16,7 & 1 & - & \\
\hline \multicolumn{7}{|l|}{ Permanência na creche } \\
\hline $\operatorname{Sim}$ & 48 & 14,2 & 14,6 & 1 & - & \\
\hline Não & 291 & 85,8 & 24,7 & 1,9 & $(0,83-4,48)$ & 0,17 \\
\hline \multicolumn{7}{|l|}{ Iniciativa em vacinar } \\
\hline Sim & 329 & 97,1 & 22,8 & 1 & - & \\
\hline Não & 10 & 2,9 & 40 & 2,2 & $(0,62-8,21)$ & 0,38 \\
\hline \multicolumn{7}{|l|}{ Conhecimento sobre vacinação } \\
\hline Erro/alguma questão & 181 & 53,4 & 20,4 & 1 & - & \\
\hline Acertou todas & 158 & 46,6 & 26,6 & 1,4 & $(0,85-2,23)$ & 0,23 \\
\hline \multicolumn{7}{|l|}{ Posto em que costuma vacinar } \\
\hline Outros & 11 & 3,2 & 18,2 & 1 & - & \\
\hline Betânia & 328 & 96,8 & 23,5 & 1,3 & $(0,29-6,53)$ & 0,96 \\
\hline $\begin{array}{l}\text { Problemas de saúde da criança que } \\
\text { contraindicam a vacinação }\end{array}$ & \multicolumn{4}{|c|}{ Problemas de saúde da criança que } & - & \\
\hline Conhece & 15 & 4,4 & 13,3 & 1 & $(0,45-9,18)$ & 0,04 \\
\hline Desconhece & 324 & 95,6 & 23,8 & 2,0 & & \\
\hline Perfil sociodemográfico & & & & & - & \\
\hline $\mathrm{B}$ e $\mathrm{C}$ & 123 & 36,3 & 20,3 & 1 & $(0,76-2,23)$ & 0,4 \\
\hline $\mathrm{D}$ e $\mathrm{E}$ & 216 & 63,7 & 25 & 1,3 & & \\
\hline Sintomas depressivos & & & & & - & \\
\hline Sem depressão & 208 & 61,4 & 23,1 & 1 & $(0,62-1,73)$ & 1,00 \\
\hline Depressão & 131 & 38,6 & 23,7 & 1,0 & & \\
\hline
\end{tabular}


sificação Econômica Brasil da Associação Brasileira de Empresas de Pesquisa (Abep). O questionário de Beck tem 21 afirmações, cujas escolhas apresentam pontuação que variam de 0 a 24 . O escore de 0 a 9 indica ausência de transtorno; de 10 a 15 indica presença de depressão leve; de 16 a 23, depressão moderada; e pontuação maior que 24 indica depressão grave ${ }^{14}$. O Questionário do Perfil Sociodemográfico do Critério de Classificação Econômica Brasil da Abep estima o poder de compra das pessoas e das famílias urbanas, diferenciando-as em classes econômicas. Possui escore que varia de 0 a 34 pontos; classe $\mathrm{A} 1$, de 30 a 34 pontos; classe $\mathrm{A} 2$, de 25 a 29 pontos; classe $\mathrm{B} 1$, de 21 a 24 pontos; classe B2, de 17 a 20 pontos; classe $\mathrm{C}$, de 11 a 16 pontos; classe $\mathrm{D}$, de 6 a 10 pontos; e classe $\mathrm{E}$, de 0 a 5 pontos $^{15}$.

A análise dos dados foi realizada pelo programa Statistical Package for the Social Sciences (SPSS). O processamento de dados foi apresentado por estatística descritiva: média, desvio padrão, mediana - para variáveis contínuas - e percentual - para variáveis categóricas. O teste estatístico do Qui-quadrado foi utilizado para análise bivariada de variáveis categóricas. Realizou-se regressão logística para a variável amamentação, cujo valor do $\mathrm{p}<0,05$ foi considerado estatisticamente significativo. Através do controle de qualidade, observou-se a concordância completa dos dados processados em $10 \%$ da população referente às variáveis: sintomas depressivos do cuidador e atraso vacinal confirmando Kappa $=1$.

Os aspectos éticos foram respeitados nesse inquérito descritivo de base populacional. O projeto de pesquisa foi aprovado pelo Comitê de Ética em Pesquisa da Universidade Luterana do Brasil e todos os participantes assinaram um termo de consentimento livre e esclarecido, conforme Resolução do CNS n ${ }^{\circ}$ 196/96.

\section{Resultados}

Das 353 crianças de 0 a 5 anos inicialmente cadastradas na ESF em 2004, na época da coleta de dados, treze não residiam mais naquele local; portanto, a população consistia, então, em 340 crianças na faixa etária de estudo. Dentre os casos analisados, um deles foi excluído durante a pesquisa, devido à mudança da família.

Os resultados referentes à convivência familiar apontaram que a média de filhos dessas famílias foi $2,73( \pm 1,68)$ e a mediana foi 2 . Na faixa etária de 0 a 5 anos, a média de idade foi de 1,38 $( \pm 0,62)$. No Jardim Betânia, a média de moradores por domicílio era $4( \pm 9,10)$.
As crianças do sexo feminino representaram $51 \%$ da população, totalizando $82,50 \%$ na faixa etária de 1 a 5 anos. No entanto, o atraso vacinal foi mais evidente nas crianças menores de 1 ano $(27,9 \%)$ e do sexo masculino $(24,1 \%)$. Em relação às variáveis sexo e faixa etária, não houve associação estatisticamente significativa.

Os cuidadores analfabetos, ou aqueles com o primário incompleto, representaram $50,1 \%$ da população em estudo. Observou-se o atraso vacinal em 27,6\% dos casos nos cuidadores que apresentavam o primário completo ou o ginasial incompleto.

As famílias pertencentes às classes $\mathrm{D}$ e $\mathrm{E}$ tinham 1,32 vez mais chances de apresentar atraso vacinal; todavia, não houve associação estatisticamente significativa ( $\mathrm{RC}=1,3$, IC 95\%, 0,62-1,73).

Constatou-se que $51,3 \%$ das crianças não foram amamentadas e que a cada mês de amamentação havia redução de um mês no atraso vacinal.

A Unidade de Estratégia Saúde da Família do Jardim Betânia foi identificada como um local para realizar a vacina em $96,8 \%$ dos casos.

No que tange ao conhecimento sobre vacinação, 53,4\% dos cuidadores erraram alguma questão referente a doenças imunopreveníveis, veracidade da contraindicação do resfriado para vacinação e conhecimento sobre qual doença seria evitada com a vacina da gotinha. Os cuidadores percebem a alimentação, a higiene e a educação como três medidas de cuidado para a saúde da criança $^{3-8}$.

A prevalência de sintomas depressivos foi de $38,6 \%$ e a prevalência de atraso vacinal de $23,3 \%$. Não foi identificada uma associação estatisticamente significativa entre os sintomas depressivos e o atraso vacinal ( $\mathrm{RC}=1,0$, IC 95\%, 0,62$1,73)$. A vacina BCG apresentou um atraso de $3,3 \%$ e a vacina oral contra a poliomielite, de $9,3 \%$ (Tabela 2).

Tabela 2. Frequência de atraso vacinal na população de 0 a 5 anos, Cachoeirinha (RS), 2005.

\begin{tabular}{llr}
\hline & $\mathbf{n}$ & $\%$ \\
\hline Atraso geral das vacinas & 79 & 23,3 \\
Contra poliomielite & 31 & 9,3 \\
Tetravalente & 20 & 6,0 \\
Tríplice bacteriana & 28 & 8,4 \\
Tríplice viral & 24 & 7,2 \\
Contra hepatite B & 17 & 5,1 \\
BCG & 11 & 3,3 \\
\hline
\end{tabular}




\section{Discussão}

Este foi um estudo que avaliou os fatores associados ao atraso vacinal. O inquérito descritivo de base populacional possibilitou gerar hipóteses entre fatores sociais, demográficos, econômicos, biológicos e o atraso vacinal. $\mathrm{O}$ estudo não detectou a associação entre a depressão e a não vacinação em dia, ou seja, não houve associação de forma estatisticamente significativa. Pode ter ocorrido um erro tipo II, ainda que o cálculo do tamanho da amostra fosse adequado para a pergunta de pesquisa, considerando que a prevalência de sintomas depressivos entre os cuidadores foi elevada, assim como a frequência de atraso vacinal da Comunidade Betânia. O resultado apresentado através da razão de chances superestimou a razão de prevalências.

Considerando que os sintomas depressivos do cuidador foram de $38,6 \%$, no presente estudo, e se o erro aceitável fosse de até 3\%, deveríamos ter pelo menos uma amostra de até 500 indivíduos para um IC 95\%.

Outra limitação foi a inexistência de questionamento sobre o aleitamento materno exclusivo ou parcial.

Nos países desenvolvidos, a depressão materna é apontada como determinante de cuidados inadequados. Estados graves de depressão podem afastar a mãe do cuidado com a criança ${ }^{13}$.

Conforme Teixeira ${ }^{16}$, a depressão é mais frequente em mulheres de baixa renda e baixa escolaridade e que residem em condições precárias com características semelhantes à comunidade estudada. A necessidade de se prestar o cuidado aos membros da família faz, muitas vezes, com que as mulheres não percebam o fato de estarem doentes ${ }^{17}$.

Vários fatores surgem como determinantes para o atraso vacinal. $O$ ato de vacinar implica uma interação entre a população e os serviços de saúde, ultrapassando o ato de uma administração oral e/ou parenteral ${ }^{7,8,18}$. As condiçõoes de vida podem levar as mães a não vacinarem adequadamente seus filhos. Este fato é mais frequente nas famílias de baixa renda, que enfrentam numerosas dificuldades diariamente. Grande parte das mulheres possui número elevado de filhos e, consequentemente, os trabalhos domésticos são grandes, por isso a disponibilidade do cuidador fica centralizada na garantia da alimentação e na busca de tratamento para os problemas de saúde. Assim, as atividades preventivas não são consideradas prioridade.

Baixa renda, extremos de idade materna, maior número de filhos, baixa escolaridade materna, maior número de moradores no domicílio, resi- dência há menos de um ano na área, falta de conhecimento acerca das doenças prevenidas por imunização e presença de doença na criança são fatores associados para a não vacinação ${ }^{19-25}$. Autores $^{7,18}$ dizem que o atraso vacinal pode estar relacionado à impossibilidade de leitura do cartão da criança por mães analfabetas, o que foi evidenciado neste estudo, em metade da amostra.

A pesquisa, cujas vacinas apresentavam três doses para a imunização das crianças, apontou um percentual de atraso mais elevado. Não foram considerados como atraso os reforços das vacinas tríplice bacteriana e viral, pois eles são indicados na faixa etária dos quatro aos seis anos, e a população em estudo era de até cinco anos.

A vacinação é um ato de cuidado que faz parte de todo ser humano, representando uma atitude de ocupação, responsabilidade e envolvimento afetivo com a criança. $\mathrm{O}$ cuidado a ela fica evidenciado, no estudo, pela participação materna. As mães acompanharam a curva de crescimento e procuravam espontaneamente a Unidade de Estratégia Saúde da Família para vacinação das crianças, em sua maioria.

$\mathrm{O}$ ato de vacinar é complexo, considerando a ocorrência de intermediação entre o cuidador, o profissional da saúde e a criança ${ }^{8,18}$. A percepção de alguns profissionais da área da saúde é que, frequentemente, as mães de classes D e E não estão conscientes da limpeza, do asseio, ou seja, da manutenção da higiene infantil. Ao contrário, neste estudo elas enfatizaram a importância do cuidado, como da higiene corporal e alimentação, mas as vacinas foram pouco citadas como medidas de prevenção ${ }^{26}$. Este fato também foi evidenciado na comunidade do Jardim Betânia. As cuidadoras reconhecem a importância do cuidado com a criança, porém têm dificuldade em colocá-lo em prática devido às suas condições sociais e econômicas.

No estudo de Bercini ${ }^{18}$, o conhecimento das mães sobre as vacinas apresentou-se, em maior ou menor grau, insuficiente e fragmentado, independentemente da escolaridade. As mães não sabiam os nomes das vacinas, as doenças que elas protegiam e quando deveriam ser aplicadas na criança. Este fato também foi detectado no Jardim Betânia, onde a maioria dos cuidadores não acertou qualquer questão referente a doenças evitáveis com a vacinação. E os problemas de saúde da criança que contraindicam a vacinação são praticamente desconhecidos dos cuidadores.

Toda vez que uma pessoa procura um serviço de saúde para receber um imunobiológico e, por algum motivo, não o recebe caracteriza uma oportunidade perdida em vacinação, muitas ve- 
zes relacionada a uma prática dos serviços de saúde. O distanciamento cultural entre o cuidador e os profissionais é um fator para o atraso vacinal. Existem atitudes negativas, como o não rastreamento do cartão de vacinas das pessoas que utilizam o serviço de saúde ${ }^{27}$. Cabe ressaltar que os registros vacinais devem ser individuais $\mathrm{e}$ de fácil acesso a todos os funcionários da sala de vacina, para que, se algum indivíduo procurar o posto de saúde sem o cartão, possa ser vacinado sem ele, e também para propiciar o chamamento das pessoas com atraso vacinal.

O Ministério da Saúde ${ }^{28}$ orienta algumas ações que devem ser seguidas para a eliminação das oportunidades perdidas em vacinação, entre elas: sensibilizar os profissionais para que se comprometam com a vacinação das pessoas que buscam os serviços de saúde; independentemente do motivo, revisar sistematicamente o cartão da criança, destacar o valor do uso do cartão de vacina, organizar e garantir o funcionamento efetivo do serviço de vacinação (com pessoal capacitado, material disponível e o quantitativo de vacinas), integrar-se com a escola para aprofundar o conhecimento sobre vacinação para estudantes, familiares e professores; criar na equipe da ESF um planejamento para o acompanhamento sistemático do calendário de vacinação.

Além dos aspectos operacionais do programa de imunização, a subjetividade do cuidado pelos profissionais é um fator preponderante para o sucesso das ações de imunização. Em populações carentes, os problemas complexos das comunidades são difíceis de serem curados, todavia o cuidado é importante como amenizador do sofrimento e apoio nos momentos de crise $\mathrm{c}^{26}$. É papel dos profissionais o apoio às comunidades no enfrentamento às dificuldades do cotidiano. Cuidar não é somente realizar com aptidão as tarefas técnicas; visa também ao acolhimento, aos vínculos de intersubjetividade e à escuta do usuário. O cuidado deve ser entendido não somente como uma prática científica, mas como um olhar para as necessidades de saúde das pessoas e dos grupos, enriquecendo as ideologias práticas, organizacionais e políticas, na visão da integralida$\mathrm{de}^{29-32}$. O apoio social refere-se a um significado de atitude emocional, simpatia, empatia, estímulo, apoio, ou seja, o poder contar com o outro, compartilhando informações pessoais ou sociais, favorecendo a resolução dos conflitos, neu- tralizando os desvios de comportamento, que são fatores determinantes para a vacinação em dia ${ }^{33}$.

A equidade nos serviços de saúde tem sido vista hoje como uma questão fundamental, em decorrência dos processos econômicos, políticos, sociais e culturais, que afetam as populações vulneráveis, embora sendo refletida pela sociedade civil $^{31}$. A pobreza é um determinante das condições de saúde das pessoas. Elas vivem em circunstâncias que as fazem sofrer mais de doenças mentais e físicas do que o restante da população. Nas camadas socioeconômicas mais baixas, as pessoas têm doenças diferentes e em maior incidência do que nas camadas médias e superiores. Além disso, os pobres usam menos os serviços de saúde. Esses problemas podem levar os carentes a sofrer de depressão. Segundo Silva ${ }^{32}$, as mães de baixa renda são provavelmente deprimidas, e sua depressão está associada à carência que enfrentam a cada dia. No presente estudo, mais da metade dos cuidadores avaliados apresentaram sintomas depressivos e foram identificados como pertencentes às classes $\mathrm{D} e \mathrm{E}$, confirmando a vulnerabilidade dessa comunidade $\mathrm{e}$ a necessidade de se intensificarem as ações de apoio específicas aos problemas sociais e mentais identificados.

$\mathrm{O}$ atendimento tradicional passivo dos profissionais da saúde torna-se inefetivo na atenção ao cuidador depressivo, especialmente em comunidades carentes. É importante disponibilizar acesso a outras práticas terapêuticas e formas de cuidado, questionando, através do diálogo, a real aplicabilidade delas como exercício de cidadania.

Cabe aos profissionais da ESF atuarem nessas transformações e conhecerem o processo dinâmico que ocorre nas famílias. A família, objeto deste estudo, possui como esteio mulheres cuidadoras, ainda que uma grande parte delas apresente sintomas depressivos. Na presente avaliação, não houve diferença entre cuidadoras com sintomas depressivos e sem eles. No entanto, provavelmente o papel de mãe é ser a fortaleza do lar, mostrando que as mulheres, mesmo doentes, encontram forças para manter o mínimo essencial para a qualidade de vida de seus filhos, caracterizando um ato de resiliência ${ }^{34-36}$. Referindo-se à cobertura vacinal, há necessidade de que os profissionais da área percebam os determinantes das condições sociais e mentais na saúde, do binômio mãe-criança, para que ajam de forma integral e humana ${ }^{37-39}$. 


\section{Colaboradores}

GC Tertuliano e AT Stein participaram igualmente de todas as etapas da elaboração do artigo.

\section{Referências}

1. Figueiredo GA, Mello DF. A prática da enfermagem na atenção à saúde da criança em unidade básica de saúde. Rev Latino-Am Enfermagem 2003; 11(4):544-551.

2. Santos SR, Cunha AJLA, Gamba CM, Machado FG, Leal Filho JMM, Moreira NLM. Avaliação da assistência à saúde da mulher e da criança em localidade urbana da região Sudeste do Brasil. Rev Saude Publica 2000; 34(3):266-271.

3. Macedo VC, Bezerra LCA, Nóbrega KBG, Frias PG, Vidal SA. Um olhar sobre a imunização no município de Recife: o grau de implantação nas equipes do PSF. Revista Nursing 2004; 76(7):45-50.

4. Miranda AS, Scheibel IM, Tavares MRG, Takeda SMP. Avaliação da cobertura vacinal do esquema básico para o primeiro ano de vida. Rev Saude Publica 1995; 29(3):208-214.

5. Gonçalves ML, Almeida MCP, Gera SC. A municipalização da vacinação em Ribeirão Preto, estado de São Paulo, Brasil. Cad Saude Publica 1996; 12(1):79-87.

6. Tavares MFL. Saúde da criança e formação no trabalho: a prática como e com saber [relatório]. Rio de Janeiro: Escola Nacional de Saúde Pública Sergio Arouca, Fundação Oswaldo Cruz; 1998.

7. Roncali AGL, Kenio C. Impacto do Programa Saúde da Família sobre indicadores de saúde da criança em municípios de grande porte da região Nordeste do Brasil. Cien Saude Colet 2006; 11(3):713-724.

8. Ibanez N, Rocha JSY, Castro PC, Ribeiro MCSA, Forster AC, Novaes MHD, Viana ALA. Avaliação do desempenho da atenção básica no estado de São Paulo. Cien Saude Colet 2006; 11(3):683-703.

9. Andrade GRB, Waitsmann J. Apoio social e redes: conectando solidariedade e saúde. Cien Saude Colet 2002; 7(4):925-934.

10. Katon W, von Korff M, Lin E, Bush T, Ormel J. Adequacy and duration of antidepressant tretment in primary care. Medical Care 1992; 30:67-76.

11. Simon GE, Von Korff M, Wagner EH, Barlow W. Patterns of antidepressant use in community practice. General Hospital Psychiatry 1993; 15:399-408.

12. Hirschfeld RMA, Keller MB, Panico S, Arons BS, Barlow D, Davidoff F, Endicott J, Froom J, Goldstein M, Gorman JM, Guthrie D, Marek RG, Maurer TA, Meyer R, Phillips K, Ross J, Schwenk TL, Sharfstein SS, Thase ME, Wyatt RJ. The National Depressive and Manic-depressive Association consensus statement on the undertreatment of depression. Journal of American Medical Association 1997; 227:333-340.

13. Carvalhaes MABL, Benicio MHA. Capacidade materna de cuidar e desnutrição infantil. Rev Saude Publica 2002; 36(2):188-197.

14. Gorenstein C, Andrade L. Inventário de depressão de Beck: propriedades psicométricas da versão em português. In: Gorenstein C, Andrade LHSG, Zuardi AW. Escalas de avaliação clínica em psiquiatria e psicofarmacologia. São Paulo: Lemos Editorial; 2000. p. 89-95. 
15. Associação Nacional de Empresas de Pesquisa (Abep). Dados com base no levantamento socioeconômico 2000. Ibope. Critério de Classificação Econômica Brasil. [acessado 2010 nov 8]. Disponível em: www.datavale-sp.com.br/CCEB.pdf

16. Teixeira MB. Empoderamento de idosos em grupos direcionados à promoção à saúde [dissertação]. Rio de Janeiro: Escola Nacional de Saúde Pública Sergio Arouca, Fundação Osvaldo Cruz; 2002.

17. Acioli S. As fronteiras da integralidade. In: Pinheiro R, Matos RA, organizadoras. Os sentidos de cuidado em práticas populares voltadas para a saúde e doença. Rio de Janeiro: Hucitec/Abrasco; 2004.

18. Bercini MA. Não vacinação: a fala das mães - um estudo de caso numa comunidade de baixa renda no município do Rio de Janeiro. Rio de Janeiro: s.n.; 1992.

19. Szwarcwald CL, Mendonça MHM, Andrade CLT. Indicadores de atenção básica em quatro municípios do estado do Rio de Janeiro, 2005: resultados de inquérito domiciliar de base populacional. Cien Saude Col 2006; 11(3):643-655.

20. López GN, Orozco E, Leyva R. Motivos de no vacunación: un análisis critico de la literatura internacional 1950-1990. Rev Saude Publica 1997; 31(3):313-321.

21. Cutts FT, Rodrigues LC, Colombo S, Bennett S. Evaluation of factors influencing vaccine uptake in Mozambique. Int J Epidemiol 1989; 18(2):427-433.

22. Marks JS, Halpin TJ, Irvin JJ, Johnson DA, Keller JR. Risk factors associated with failure to receive vaccination. Pediatrics 1979; 64(3):304-309.

23. Markland RE, Durand DE. An investigation of socio-psychological factors affecting infant immunization. Am J Public Health 1976; 66:168-170.

24. Szwarcwald CL, Valente JC. Avaliação da cobertura de vacinação em Teresina - Piauí (Brasil, 1983). Cad Saude Publica 1985; 1(1):41-49.

25. Silva EA, Vasques FS. Investigação vacinal: uma ação preventiva em pacientes internados. Nursing $200 ; 1(1): 28-34$

26. Lacerda A, Valla VV. As práticas terapêuticas de Cuidado Integral à Saúde como proposta para aliviar o sofrimento. In: Pinheiro R, Matos RA, organizadores. Cuidado e integralidade por uma genealogia de saberes e práticas do cotidiano. Rio de Janeiro: Hucitec-Abrasco; 2004. p. 21-36.

27. Matos RA. As fronteiras da integralidade. In: Pinheiro R, Matos RA, organizadores. Cuidado prudente para uma vida decente. Rio de Janeiro: HucitecAbrasco; 2004. p. 119-132.

28. Brasil. Fundação Nacional de Saúde (Funasa). Manual de procedimentos de vacinação. Brasília: $\mathrm{Fu}-$ nasa; 2001.

29. Szwarcwald CL, Mendonça MHM, Andrade CLT. Indicadores de atenção básica em quatro municípios do estado do Rio de Janeiro, 2005: resultados de inquérito domiciliar de base populacional. Cien Saude Colet 2006; 11(3):643-655.
30. Teixeira MB. Empoderamento de idosos em grupos direcionados à promoção à saúde [dissertação]. Rio de Janeiro: Escola Nacional de Saúde Pública Sergio Arouca, Fundação Osvaldo Cruz; 2002.

31. Luz MT. As fronteiras da integralidade. In: Pinheiro R, Matos RA, organizadores. Fragilidade social e busca de cuidado na sociedade civil de hoje. Rio de Janeiro: Hucitec-Abrasco; 2004. p. 9-20.

32. Silva TM. Saúde, desenvolvimento e globalização: um desafio para os gestores do terceiro milênio. In: Cianciarullo TI, Corneta VK, organizadores. A pobreza e a saúde: que perspectiva de vida saudável teremos para o século XXI? São Paulo: Ícone; 2002.

33. Sapienza G, Pedromônico MRM. Risco, proteção e resiliência no desenvolvimento da criança e do adolescente. Psicologia em Estudo 2005; 10(2):209-216.

34. Koller SH. Resiliência e vulnerabilidade em crianças que trabalham na rua. Educar em Revista [periódico na Internet]. 1999. [acessado 2010 nov 8]; 15[4p.]. Disponível em: http://www.universiabrasil. net/teses

35. Kotliarenco MA, Cáceres I, Fontecilla M. Estado de arte em resiliência. UK: Oficina Sanitaria Panamericana Opas, Oficina Regional de la Organización Mundial de la Salud; 1997.

36. Lordelo ER, Fonseca AL, Araujo MLVB. Responsividade do ambiente de desenvolvimento: crenças e práticas como sistema cultural de criação de filhos. Psicol Reflex Crit 2000; 13(1):73-80.

37. Moraes JC, Ribeiro MCSA, Simões O, Castro PC, Barata RB. Qual é a cobertura vacinal real? Epidemiologia e Serviços de Saúde 2003; 12(3):147-153.

38. Santos DM, Dubeux LS, Frias PG, Vanderlei LCM, Vidal SA. Avaliação normativa da ação programática: imunização nas equipes de saúde da família do município de Olinda, estado de Pernambuco, Brasil, em 2003. Epidemiologia e Serviços de Saúde 2006; 15(3):29-35.

39. Tertuliano GC. Sintomas depressivos do cuidador, pobreza e atraso vacinal em crianças: um estudo de base populacional [dissertação]. Canoas: Universidade Luterana do Brasil; 2006.

Artigo apresentado em 06/05/2007

Aprovado em 16/05/2008

Versão final apresentada em 12/11/2008 